\title{
Temozolomide as a monotherapy for treatment of Glioblastoma Multiforme in elderly patients with poor performance status
}

\author{
Authors \\ Dr Amit Kichloo ${ }^{1 *}$, Dr Rajan Yadav², Dr Sakina Mankada ${ }^{3}$, Dr U.Surayanarayan ${ }^{4}$ \\ ${ }^{1} 2^{\text {nd }}$ year resident Radiotherapy Department, GCRI \\ ${ }^{2}$ Assistant Professor Radiotherapy Department, GCRI \\ ${ }^{3} 2^{\text {nd }}$ year Resident Radiotherapy Department, GCRI \\ ${ }^{4}$ Professor and Head of Department, Radiotherapy Department, GCRI
}

\section{Introduction}

Glioblastoma is the most aggressive and most common primary malignant brain tumor in elderly population. The median age of presentation is sixty four years. The frequency in age group of more than seventy years has increased over past decade and it is rising in developed countries. Age is the most important independent prognostic factor.

The standard treatment regimen for non elderly patients is maximal safe resection followed by six weeks of concurrent involved field radiotherapy with temozolomide followed by six month of adjuvant temozolomide. This chemo radiation regimen was first published as a prospective randomized trial by STUPP et al in 2005 . The trial concluded an improvement in median overall survival of 2.5 months over radiation alone but patients more than 70 years were excluded from the study \& thus the treatment in this subgroup was less clear. Moreover the tolerability of combined temozolomide and radiation seems to be reduced in the elderly population but temozolomide alone has shown promising results. RT (Radiation Treatment) alone seems to be less effective in prolonging survival. the two major reasons may be either less effectivness against the tumor or more toxic to elderly patients because of limited cerebral reserve and more risk of cognitive side effect from cranial irradiation. Elderly patients are also more susceptible to RT induced leukoencephalopathy, brain atrophy and ultimately dementia due to presence of pre existing vascular changes.

In contrast to radiation, temozolomide can be started quickly after diagnosis even from a local hospital. Moreover outpatient treatment and shorter treatment duration could lessen the burden on medical resources and reduce the risk of treatment being withheld.

Due to under representation of elderly patients with glioblastoma in clinical trials, there is a unsatisfactory data for treatment and they may be routinely undertreated to avoid toxicity given uncertain therapeutic efficacy from standard therapy .Thus we reviewed current literature on treatment of elderly patients with glioblastoma and emphasize the importance of temozolomide as a monotherapy in this population group. 
Temozolomide alone in elderly patients with glioblastoma

Various groups of investigators explored the use of temozolomide in elderly patients with poor performance status (table 1).

Chinot et al performed a prospective single arm phase II study in patients more than 70 years of age with use of temozolomide as a same dose used as adjuvant dose regimen by STUPP et al . The observed PFS \& OS was 5 months and 6.4 months respectively. Less than $10 \%$ of patients had significant hematological toxicities and dose reduction was needed in only $14 \%$ of temozolomide cycles. This study concluded that temozolomide can be considered as a reasonable monotherapy for newly diagnosed glioblastoma in elderly patients.

A prospective single arm phase II trial by ANOCEF among elderly patients with newly diagnosed glioblastoma with dose of $150-200$ $\mathrm{mg} / \mathrm{m} 2$ per day for 5 days out of each 28 day cycle with median OS 6.25 months which was better than the reported controls who received best supportive care only.

\begin{tabular}{|c|c|c|c|c|c|c|c|}
\hline STUDY & $\begin{array}{c}\text { NO. OF } \\
\text { PATIEN } \\
T \\
\end{array}$ & AGE & KPS & TREATMENT & $\begin{array}{c}\text { MEDIAN } \\
\text { OS } \\
\text { (MONTHS) }\end{array}$ & $\begin{array}{l}\text { MEDIAN PFS } \\
\text { (MONTHS) }\end{array}$ & REFERENCES \\
\hline $\begin{array}{l}\text { PROSPECTIVE } \\
\text { randomised }\end{array}$ & $\begin{array}{l}195 \\
178\end{array}$ & 65 & $<60$ & $\begin{array}{l}\text { TMZ(alone) } \\
\text { RT(alone) }\end{array}$ & $\begin{array}{l}8.6 \\
9.6\end{array}$ & $\begin{array}{l}3.3 \\
4.7\end{array}$ & $\begin{array}{c}\text { WICK } \\
(\text { NOA-08) }\end{array}$ \\
\hline $\begin{array}{l}\text { RETROSPECTIVE } \\
\text { cohort }\end{array}$ & $\begin{array}{l}32 \\
54\end{array}$ & 70 & $<60$ & $\begin{array}{l}\text { TMZ(alone) } \\
\text { RT(alone) }\end{array}$ & $\begin{array}{c}6 \\
4.1 \\
\end{array}$ & NA & GLANTZ \\
\hline $\begin{array}{l}\text { PROSPECTIVE } \\
\text { Single arm }\end{array}$ & 32 & 70 & $<60$ & TMZ(alone) & 6.4 & 5 & CHINOT \\
\hline $\begin{array}{l}\text { PROSPECTIVE } \\
\text { singlearm }\end{array}$ & 70 & 70 & $<70$ & TMZ(alone) & 6.25 & 4 & $\begin{array}{l}\text { GALLEGO } \\
\text { (ANOCEF) }\end{array}$ \\
\hline $\begin{array}{l}\text { PROSPECTIVE } \\
\text { randomised }\end{array}$ & $\begin{array}{c}93 \\
100\end{array}$ & 65 & & $\begin{array}{l}\text { TMZ(alone) } \\
\text { RT(alone) }\end{array}$ & $\begin{array}{c}8.3 \\
6\end{array}$ & $\begin{array}{l}\text { NA } \\
\text { NA }\end{array}$ & $\begin{array}{l}\text { MALMSTROM } \\
\text { (NORDIC) }\end{array}$ \\
\hline
\end{tabular}

NOA-08 randomized phase III trial between May15, 2005 to Nov2, 2009 enrolled patients with anaplastic astrocytoma and glioblastoma more than 65 years with kps score of 60 or higher. The patients were randomized to $100 \mathrm{mg} / \mathrm{m} 2$ temozolomide on day 1 to day 7 of week 1 on, 1 week off cycle or radiotherapy of $60 \mathrm{~Gy}$ in 6 to 7 weeks at 2 Gy per fraction in 30 fractions. The median overall survival was 8.6 months in temozolomide group versus 9.6 months in radiotherapy group with no significant difference in median EFS between the two groups. The interpretation of this trial was that temozolomide alone is non inferior to RT alone in treatment of elderly patients with malignant astrocytoma.

Retrospective cohort study (Glantz et al) included 86 patients with age 70 or older with malignant glioma from three institutes, out of which 32 received monthly temozolomide $150-200 \mathrm{mg} / \mathrm{m} 2$ everyday for 5 days every 28 days and rest 54 patients received RT as a initial therapy. The median survival was 6 months and 4.1 months, and 1 year survival rate was $11.9 \%$ and $9.3 \%$ for temozolomide and RT group respectively. The difference in survival was not statistically significant and $75 \%$ of the patients who received temozolomide died at home compared with $61 \%$ who received only rt. With these results the study concluded that temozolomide is an alternative and perhaps superior therapeutic option to irradiation.

NORDIC randomized phase III trial enrolled patients more than 60 years with glioblastoma from 7 countries in three groups: temozolomide $200 \mathrm{mg} / \mathrm{m} 2$ on days 1 to 5 of every 28 days up to 6 cycles or hypofractionated radiotherapy 34 Gy with 3.4 Gy per fraction over 2 weeks or standard radiotherapy 60 Gy with 2 Gy per fraction over 6 weeks. In three group randomization median OS was longer with temozolomide of 8.3 months versus 6 months with standard radiotherapy but another randomization between groups temozolomide versus hypofractionated 
radiotherapy had OS similar. Interpretation of this trial was that both temozolomide and hypofractionated RT should be considered as a standard treatment options in elderly patients with glioblastoma as compared to standard RT which was associated with poor outcomes.

\section{Conclusion}

Temozolomide has an acceptable safety profile in elderly patients with newly diagnosed glioblastoma and poor performance status. Temozolomide alone is non inferior to radiotherapy alone and adds a new option to the care of newly diagnosed elderly patients with glioma. Accumulated data suggests that elderly patients do benefit from active anti tumor therapy and that temozolomide chemotherapy might be a valid alternative to a standard irradiation. Temozolomide is alternative perhaps a superior therapeutic option to irradiation based on its ease of administration and low morbidity. Daily trip to hospital for radiation may decrease the quality of life due to excessive fatigue and increase neurological deficit in elderly poor performance status patients .many patients are unable to complete planned standard RT regimen and discontinue the RT treatment. In a disease with poor prognosis, elderly patients with glioblastoma fare worse than non elderly patients. Surgical resection of newly diagnosed glioblastoma is associated with improved survival regardless of patients age and thus attempt should be made for maximum safe resection. Involved field radiation therapy is also effective therapy. A dose of $60 \mathrm{~Gy}$ given over 6 weeks is the standard of care for younger patients but data suggest that hypofractionated radiation (34 to $40 \mathrm{~Gy}$ ) may provide similar survival benefit with less toxicity. temozolomide either monotherapy or adjuvant to radiation is associated with improved survival. The trials fordata for standard dose regimen for temozolomide as as monotherapy are currently underway.

\section{References}

1. Temozolomide in Elderly Patients With Newly Diagnosed Glioblastoma and Poor Performance Status: An ANOCEF Phase II TrialJaime Ga'llego Pe'rez-Larraya, Franc sois Ducray, Olivier Chinot, Isabelle Catry-Thomas, Luc Taillandier, JeanSe'bastien Guillamo, Chantal Campello, Annick Monjour, Ste'phanie CartalatCarel, Maryline Barrie, Aymeri Huchet, Patrick Beauchesne, Mona Matta, Karima Mokhtari, Marie-Laure Tanguy, Je'rôme Honnorat, and Jean-Yves Delattre

2. Keime-Guibert F, Chinot O, Taillandier L, et al: Radiotherapy for glioblastoma in the elderly. N Engl J Med 356:1527-1535, 2007

3. Roa W, Brasher PM, Bauman G, et al: Abbreviated course of radiation therapy in older patients with glioblastoma multiforme: A prospective randomized clinical trial. J Clin Oncol 22:1583-1588, 2004

4. Glantz M, Chamberlain M, Liu Q, et al: Temozolomide as an alternative to irradiation for elderly patients with newly diagnosed malignant gliomas.Cancer 97:2262-2266, 2003

5. Chinot OL, Barrie M, Frauger E, et al: Phase II study of temozolomide without radiotherapy in newly diagnosed glioblastoma multiforme in an el-derly population. Cancer 100:2208-2214, 2004

6. Wick W, Engel C, Combs SE, et al: NOA08 randomized phase III trial of 1-weekon/1-week-off temozolomide versus involved-field radiotherapy in elderly (older than age 65) patients with newly diagnosed anaplastic astrocytoma or glioblastoma (Methusalem). J Clin Oncol 28:180s, 2010 (supplabstr LBA2001)

7. Malmstrom A, Grønberg BH, Stupp R, et al:Glioblastoma (GBM) in elderly patients: A randomized phase III trial comparing survival in patients treated with 6-week 
radiotherapy (RT) versus hypofractionated RT over 2 weeks versus temozolomide single-agent chemotherapy (TMZ). J Clin Oncol 28:180s, 2010 (suppl; abstr LBA2002)

8. Laigle-Donadey F, Delattre JY: Glioma in the elderly. Curr Opin Oncol 18:644-647, 2006.

9. Desai A, Grolleau-Julius A, Yung R: Leukocyte function in the aging immune system. J Leukoc Biol 87:1001-1009, 2010

10. Hess KR, Broglio KR, Bondy ML: Adult glioma incidence trends in the United States, 1977-2000 Cancer 101:2293-2299,2004

11. Yee KW, Pater JL, Pho L, et al: Enrollment of older patients in cancer treatment trials in Canada:Why is age a barrier? J Clin Oncol 21:1618-1623, 2003. 